\title{
Correlações entre contagem bacteriana total e parâmetros de qualidade do leite*
}

\section{Correlations between total bacterial count and quality parameters of milk}

\author{
Diego Prado de Vargas, ${ }^{* *}$ José Laerte Nörnberg, ${ }^{* *}$ Renius de Oliveira Mello, ${ }^{* *}$ Rudolf Brand Sheibler, ${ }^{* * *}$ \\ Marceli Pazini Milani, ${ }^{* *}$ Fernanda Cristina Breda Mello****
}

\begin{abstract}
Resumo
Objetivou-se avaliar o efeito da contagem bacteriana total (CBT) sobre os constituintes do leite, verificando a influência que as variáveis climáticas exercem sobre a CBT. Os dados utilizados foram de 1.541 unidades produtoras de leite, referentes a 15 municípios da bacia leiteira do Vale do Taquari, Rio Grande do Sul. Foram tabulados os dados de CBT, contagem de células somáticas (CCS) e composição centesimal do leite, referentes ao período de junho de 2008 a dezembro de 2011 , totalizando 44.089 amostras analisadas. As variáveis climáticas (médias mensais da temperatura média, da umidade relativa do ar e precipitação pluviométrica) não apresentaram correlação significativa com a CBT. Os teores de gordura, proteína, minerais e sólidos totais foram diretamente correlacionados com a CBT, enquanto os sólidos não gordurosos e a lactose apresentaram comportamento inverso. Através da análise de componentes principais (ACP), auxiliada pelo método hierárquico aglomerativo de agrupamento, os sete tratamentos presentes no estudo foram reduzidos a quatro grupos de acordo com a similaridade. Assim, os leites com CBT superiores a 50.000 até 500.000 UFC mL-1, e ainda de valores acima de 500.000 até $1.000 .000 \mathrm{UFC} \mathrm{mL}^{-1}$ apresentam a mesma qualidade química e contagem de células somáticas, não justificando a estratificação de intervalos nesta amplitude de variação para avaliação do efeito da CBT nestes indicadores de qualidade.
\end{abstract}

Palavras-chave: composição química do leite, mastite, qualidade higiênico-sanitária do leite, variáveis climáticas.

\begin{abstract}
The study aims to evaluate the effect of total bacterial count (TBC) on the milk constituents and the influence of the environmental conditions has on the TBC. Data were obtained from 1,541 dairy farms located in 15 municipalities in the dairy region of Vale do Taquari, Rio Grande do Sul. It was tabulated the data from TBC, somatic cell count (SCC) and milk composition, from June 2008 to December 2011, totaling 44,089 samples. The climatic variables have no significant correlation to TBC. The fat, protein, minerals and total solids were directly correlated with the TBC. While solids-not-fat and lactose showed an opposite behavior. Through of the principal component analysis (PCA), followed by agglomerative hierarchical clustering method, the seven treatments in the present study were reduced to four groups according to similarity, showing that milk with TBC above 50,000 to $500,000 \mathrm{CFU}^{\mathrm{mL}} \mathrm{T}^{-1}$ and 500,000 to $1,000,000 \mathrm{CFU} \mathrm{mL}^{-1}$, have the same chemical quality and SCC, not justifying the stratification intervals in this range of variation for evaluating the milk quality.
\end{abstract}

Keywords: chemical composition of milk, climatic variables, mastitis, milk hygienic-sanitary quality.

\section{Introdução}

O leite cru pode ser contaminado por grande variedade de micro-organismos provenientes de diversas fontes. Entre os micro-organismos patogênicos e/ou deteriorantes que podem ser encontrados, destacam-se as bactérias acidolácticas (Lactococcus, Lactobacillus spp., Leuconostoc, Enterococcus ou Streptococcus spp.), Pseudomonas spp., bactérias pertencentes à família Micrococcaceae (Micrococcus e Staphylococcus spp.) e leveduras. Outros grupos microbianos presentes no leite cru incluem Bacillus, Clostridium, Listeria spp. e enterobactérias (Tebaldi et al., 2008).

Nero et al. (2005) relataram uma alta frequência de amostras de leite in natura com elevados níveis de contaminação por aeróbios mesófilos, que são os principais micro-organismos responsáveis pelo metabolismo da lactose, levando à produção de ácido lático, no qual em quantidades elevadas, pode desestabilizar a caseína. No entanto, o armazenamento do leite cru sob refrigeração possibilita a redução de perdas referentes à qualidade da

*Recebido em 4 de setembro de 2013 e aceito em 10 de janeiro de 2014.

**Departamentode Tecnologia e Ciência dos Alimentos (DTCA) da Universidade Federal de Santa Maria

***Departamento de Zootecnia da Universidade Federal de Pelotas

****Departamento de Zootecnia da Universidade Federal de Santa Maria

Autor para Correspondência: diegodevargas@hotmail.com 
matéria-prima pela atividade acidificante de bactérias mesófilas, porém, quando realizado por períodos prolongados, pode resultar em queda de qualidade dos produtos lácteos, devido ao crescimento e à atividade enzimática de bactérias psicotróficas (Vidal-Martins et al., 2005).

Nesse contexto, a determinação da contagem bacteriana total (CBT) do leite de tanques de expansão é importante para avaliação da higiene de ordenha e das condições de estocagem e transporte do leite cru, sendo uma importante ferramenta no controle da qualidade da matériaprima, permitindo inferir sobre os prováveis efeitos indesejáveis acerca do rendimento industrial de produtos lácteos. Além disso, o leite com elevada CBT representa risco para a saúde do consumidor, pelo potencial de veiculação de micro-organismos e toxinas microbianas.

Diante do exposto e devido à ausência de uma descrição científica mais consistente que caracterize as associações existentes entre CBT e variáveis importantes para a qualidade do leite, como os teores de gordura, proteína, lactose, minerais, sólidos totais, sólidos não gordurosos e a contagem de células somáticas, objetivou-se analisar as correlações existentes entre a CBT e estes parâmetros de qualidade, bem como avaliar a influência que as variáveis climáticas exercem sobre a CBT.

\section{Material e métodos}

Os dados utilizados foram obtidos a partir dos laudos oficiais emitidos pelo Laboratório de Serviço de Análises de Rebanhos Leiteiros (SARLE), órgão credenciado junto ao Ministério da Agricultura, Pecuária e Abastecimento (MAPA), os quais continham 54.696 registros de gordura (GORD), proteína (PROT), lactose (LACT), sólidos não gordurosos (SND), sólidos totais (ST), contagem bacteriana total (CBT) e contagem de células somáticas (CCS), obtidos de amostras de leite coletados em tanque de expansão de 1.706 propriedades, durante o período de junho de 2008 a dezembro de 2011. A GORD, PROT, LACT, ST e SNG foram determinados por espectrofotometria com radiação infravermelha utilizando equipamento Bentley ${ }^{\circledR}$ 2000 (Bentley Instruments, Chaska, MN, EUA), enquanto a CBT e a CCS por citometria de fluxo utilizando equipamento Bactocount $^{\circledR}$ IBC (Bentley Instruments, Chaska, MN, EUA) e Somacount $^{\circledR} 300$ (Bentley Instruments, Chaska, MN, EUA), respectivamente.

Os dados meteorológicos das médias mensais da temperatura média, umidade relativa do ar (URA) e precipitação pluviométrica, referentes ao período experimental foram obtidos no Instituto Nacional de Meteorologia (INMET), situado em Brasília, Distrito Federal, a partir da estação climática em Teutônia/RS.

Para obtenção da consistência do banco de dados, os registros foram considerados em classes mensais e, excluídos do arquivo, propriedades com menos de quatro controles e com três desvios padrão acima ou abaixo da média da característica no mês. Após as restrições, foram utilizados nas análises estatísticas 44.089 registros de 1.541 rebanhos, referentes a 15 municípios, localizados na região sul do Brasil.

Com o intuito de linearizar os dados, a CBT foi transformada em logaritmo natural da CBT normal (log da CBT) e a CCS pelo escore linear de células somáticas $E C S=\left[\log _{2}(C C S / 100)\right]+3$ (Shook, 1993). Após edição e linearização, os dados apresentaram a estatística descritiva demonstrada na Tabela 1.

Tabela 1: Estatística descritiva contendo os valores mínimos, máximos, médias, desvios padrão (DP) e coeficientes de variação $(C V)$ das variáveis gordura, proteína, ( somáticas (CCS), escore linear da contagem de células somáticas (ECS),

\begin{tabular}{lccccc}
\hline \multicolumn{1}{c}{ Variável } & Mínimo & Máximo & Média & DP & CV (\%) \\
\hline Gordura, \% & 2,20 & 5,10 & 3,58 & 0,37 & 10,42 \\
Proteína, \% & 2,29 & 3,91 & 3,09 & 0,21 & 6,87 \\
Lactose, \% & 3,65 & 4,91 & 4,34 & 0,16 & 3,66 \\
Minerais, \% & 0,39 & 1,51 & 0,97 & 0,10 & 10,13 \\
Sólidos não gordurosos, \% & 7,16 & 9,71 & 8,39 & 0,83 & 9,95 \\
Sólidos totais, \% & 9,99 & 14,07 & 11,98 & 0,57 & 4,79 \\
CCS, cél mL-1 & $1.000,00$ & $2.729 .000,00$ & $711.883,87$ & $491.555,81$ & 69,05 \\
ECS, adimensional & 6,32 & 17,73 & 15,43 & 1.14 & 7,39 \\
CBT, UFC mL-1 & $1.000,00$ & $3.700 .000,00$ & $2.963 .667,54$ & $3.208 .240,03$ & 163,38 \\
CBT, log UFC mL-1 & 6,91 & 15,12 & 14,14 & 1.45 & 10,01 \\
\hline
\end{tabular}

Os dados de CBT foram divididos em sete (7) classes estabelecidas de acordo com seus valores regulatórios (Brasil, 2002; Bulletin, 2006; Brasil, 2011). As classes avaliadas foram: (1) $\mathrm{CBT} \leq 50.000$ UFC mL-1; (2) $50.000<\mathrm{CBT}^{-100.000 ~ U F C}$ $\mathrm{mL}^{-1}$; (3) $100.000<\mathrm{CBT} \leq 500.000$ UFC mL-1; (4) $500.000<$ $\mathrm{CBT} \leq 600.000$ UFC mL $\mathrm{m}^{-1}$; (5) $600.000<\mathrm{CBT} \leq 750.000$ UFC $\mathrm{mL}^{-1}$; (6) $750.000<\mathrm{CBT} \leq 1000.000$ UFC mL $\mathrm{mL}^{-1}$; e (7) CBT > 1.000.000 UFC mL-1.

As variáveis dependentes (GORD, PROT, LACT, minerais, SNG, ST e CCS) foram testadas quanto à normalidade residual pelo teste de Kolmogorov-Smirnov e quanto à homocedasticidade pelo teste de Levene. Posteriormente, foram submetidas à análise de variância univariada pelo procedimento de modelos lineares gerais (PROC GLM) em delineamento inteiramente casualizado. Em seguida, as médias foram ajustadas pelo método dos quadrados mínimos ordinários com o comando LSMEANS (Least Squares Means) e comparadas pelo teste de Tukey ao nível de $5 \%$ de significância.

Além disso, foi realizada análise de correlação linear simples do log da CBT normal com as variáveis GORD, PROT, LACT, minerais, SNG, ST e ECS. Adicionalmente, também foi efetuada análise de correlação linear simples do log da CBT normal com as variáveis meteorológicas (médias mensais da temperatura média, da umidade relativa do ar e da precipitação pluviométrica).

Para reduzir a dimensionalidade do conjunto original de variáveis com menor perda de informação possível, procedeu-se à análise de variância multivariada pelo procedimento GLM e o comando MANOVA.

As variáveis empregadas na análise multivariada foram GORD, PROT, LACT, minerais e ECS. As demais variáveis foram 
eliminadas do modelo devido às altas correlações existentes entre as mesmas, formando matrizes de dispersão singulares e causando problemas de multicolinearidade ou dependência linear entre as variáveis.

$\mathrm{Na}$ análise multivariada, para testar a hipótese de que os vetores de médias dos tratamentos (classes de CBT) fossem nulos, foi realizado o teste de Wilks. Após, foi efetuada a análise de componentes principais - ACP (Principal Component Analysis $P C A$ ) para ordenação das classes de $C B T$, sendo uma técnica de análise multivariada que permite o agrupamento de acordo com a similaridade, mediante o exame visual das dispersões gráficas. Salienta-se que, para melhor interpretação dos resultados, foi feita a padronização dos dados de forma que apresentassem média zero e variância igual a um, ou seja, com base na matriz de correlação.

Todavia, conforme inspeção gráfica visual, não se pôde concluir sobre o número ideal de grupos entre tratamentos. Dessa forma, procedeu-se à análise de agrupamento (Cluster Analysis) utilizando-se o algoritmo hierárquico aglomerativo de Ward como método de agrupamento e a distância euclidiana quadrática como medida de dissimilaridade e, juntamente com o auxílio estatístico do coeficiente de correlação cofenético (CCC), pseudo-F e pseudo- $\mathrm{t}^{2}$, foi determinado o número ideal de grupos entre tratamentos.

A análise de componentes principais foi executada com o procedimento PRINCOMP, enquanto a análise de agrupamento o foi com o procedimento CLUSTER.

As análises estatísticas foram executadas no aplicativo SAS ${ }^{\circledR}$ System for Windows ${ }^{\mathrm{TM}}$ versão 9.0 (SAS Institute Inc., Cary NC, USA).

\section{Resultados e discussão}

Com a elevação da contaminação bacteriana, houve redução significativa $(P<0,05)$ apenas no teor de lactose e sólidos não gordurosos. Ao mesmo tempo, aumentaram as concentrações de gordura, proteína, minerais, sólidos totais e ECS do leite $(P<0,05)$ (Tabela 2). Da mesma maneira, Bueno et al. (2008) observaram este mesmo comportamento para as variáveis gordura, proteína e lactose, à medida que se elevaram os valores de CBT do leite.

Entretanto, o aumento nos teores de gordura, proteína e minerais não deve ser considerado favorável à qualidade do leite, pois a elevação simultânea do ECS (Tabela 2) evidencia a presença de um processo inflamatório da glândula mamária e, assim, o incremento nos valores destas variáveis possivelmente seja resultante da redução na produção de leite, que é mais acentuada que a redução da síntese destes constituintes, ocorrendo concentração relativa dos teores de gordura, proteína e minerais (Machado et al., 2000).

Neste sentido, a elevação da contaminação bacteriana do leite, medido por meio da CBT de tanques de expansão, pode ser influenciada por todos os utensílios que entram em contato com o leite, pele de tetos e úbere, bem como glândula mamária infectada, principalmente por Streptococcus agalactiae e outros estreptococos causadores de mastite subclínica (Zakoks et al., 2004). Assim, o aumento concomitante da CCS, deve-se provavelmente à elevação da incidência de mastite subclínica por bactérias do gênero estreptococos, que conjuntamente com deficiências higiênico-sanitárias relacionadas com o processo produtivo do leite, pode contribuir de maneira significativa com o aumento da CBT do tanque de expansão. Este fato reforçase nos achados de Lopes Júnior et al. (2012), onde em estudo realizado em 638 quartos mamários, com objetivo de estabelecer a relação entre CBT e CCS de acordo com os patógenos da mastite, evidenciaram que a correlação de Pearson e Spearman entre estas variáveis foi maior que 0,60 para todos os patógenos e o coeficiente angular das regressões lineares mostraram diferentes aumentos da CBT com o mesmo aumento da CCS, sendo que o maior coeficiente angular encontrado foi para o Streptococcus agalactiae (0.542), seguido do Streptococcus aureus $(0,503)$ e outros estreptococos $(0.486)$.

Por outro lado, Andrade et al. (2009) observaram diminuição na concentração de gordura com a elevação da CBT, o que poderia estar relacionado com a ação de fosfolipases de origem bacteriana, principalmente a fosfolipase $\mathrm{C}$ e a lecitinase, das bactérias psicotróficas, que são micro-organismos capazes de se desenvolver em temperaturas abaixo de $7^{\circ} \mathrm{C}$, sendo os principais agentes de deterioração do leite cru refrigerado (Martins et al., 2005). Essas enzimas podem contribuir com a hidrólise dos triglicerídeos (Chen et al., 2003), originando ácidos graxos livres (AGL), que quando presentes acima de limites de tolerância contribuem para o efeito negativo sobre o sabor conhecido como rancidez ou rancidez hidrolítica (Hanuš et al., 2008).

Da mesma maneira, em discordância com os resultados deste estudo, estes mesmos autores encontraram decréscimo no teor de proteína com a elevação da CBT, o que poderia ser decorrente da expressiva redução da fração de caseína. Nesse sentido, quando a contagem bacteriana do leite é elevada, os microorganismos psicrotróficos presentes podem produzir proteases extracelulares que contribuem de maneira significativa para a degradação de proteínas (Vidal-Martins et al., 2005), provocando desestabilização da micela caseínica e, consequentemente, coagulação do leite, alteração da composição proteica e acúmulo de pequenos peptídeos, os quais são responsáveis pelo desenvolvimento de sabor amargo e adstringente (Ma et al., 2000).

Portanto, apesar de ter sido encontrado um aumento na concentração total da gordura e proteína (Tabela 2), a determinação das concentrações de caseína e AGL poderiam elucidar os questionamentos sobre a possível limitação das metodologias utilizadas, principalmente em relação a prováveis alterações qualitativas na gordura e proteína, o que ocasionariam restrições a sistemas de pagamento com base somente na composição centesimal do leite sem considerar a CBT.

Os teores de lactose diminuíram $(\mathrm{P}<0,05)$ com o incremento da CBT (Tabela 2). De forma semelhante, Bueno et al. (2008) encontraram redução na concentração da lactose com a elevação dos valores de CBT do leite.

A diminuição dos valores da lactose com o aumento da contaminação bacteriana, provavelmente deve-se à ação direta de patógenos mamários que utilizam como principal substrato, este carboidrato (Harmon, 1994). Assim, de maneira geral, pode-se dizer que os micro-organismos mesófilos predominam em situações que há falta de condições básicas de higiene e deficiências relacionadas com a refrigeração do leite. Em tais circunstâncias, bactérias como Lactobacillus, Streptococos, Lactococos e algumas enterobactérias, atuam intensamente através da fermentação da lactose, produzindo ácido láctico e, consequentemente, acidez do leite, que é um dos problemas 
Tabela 2: Médias ajustadas dos teores de gordura (Gord), proteína (Prot), lactose (Lact), minerais (Min), sólidos não gordurosos (SNG), sólidos totais (ST) e do logaritmo natural da contagem bacteriana total (CBT) com seus respectivos erros padrão da média (entre parênteses) em função das distintas classes de contagem de células somáticas (CCS)

\begin{tabular}{|c|c|c|c|c|c|c|c|}
\hline $\begin{array}{c}\text { CBT } \\
\left(\times 10^{3} \text { UFC } \mathrm{mL}^{-1}\right)\end{array}$ & $\begin{array}{l}\text { Gord } \\
(\%)\end{array}$ & $\begin{array}{l}\text { Prot } \\
(\%)\end{array}$ & $\begin{array}{l}\text { Lact } \\
(\%)\end{array}$ & $\begin{array}{l}\text { Min } \\
(\%)\end{array}$ & $\begin{array}{l}\text { SNG } \\
(\%)\end{array}$ & $\begin{array}{l}\text { ST } \\
(\%)\end{array}$ & $\begin{array}{c}\text { ECS }^{3} \\
{\left[\log _{2}(\mathrm{CCS} / 100)\right]+3}\end{array}$ \\
\hline $\mathrm{CBT} \leq 50$ & $\begin{array}{c}3,47^{d} \\
(0,012)\end{array}$ & $\begin{array}{c}3,08^{\mathrm{b}} \\
(0,007)\end{array}$ & $\begin{array}{c}4,42^{\mathrm{a}} \\
(0,005)\end{array}$ & $\begin{array}{l}0,956^{b} \\
(0,003)\end{array}$ & $\begin{array}{l}8,45^{\mathrm{ab}} \\
(0,010)\end{array}$ & $\begin{array}{l}11,92^{b} \\
(0,018)\end{array}$ & $\begin{array}{l}15,22^{c} \\
(0,035)\end{array}$ \\
\hline $50<\mathrm{CBT} \leq 100$ & $\begin{array}{c}3,50^{d} \\
(0,009)\end{array}$ & $\begin{array}{c}3,09^{b} \\
(0,005)\end{array}$ & $\begin{array}{c}4,41^{\mathrm{a}} \\
(0,004)\end{array}$ & $\begin{array}{l}0,964^{\mathrm{ab}} \\
(0,002)\end{array}$ & $\begin{array}{c}8,46^{\mathrm{a}} \\
(0,008)\end{array}$ & $\begin{array}{l}11,96^{\mathrm{ab}} \\
(0,015)\end{array}$ & $\begin{array}{l}15,33^{b} \\
(0,029)\end{array}$ \\
\hline $100<\mathrm{CBT} \leq 500$ & $\begin{array}{c}3,53^{c} \\
(0,004)\end{array}$ & $\begin{array}{c}3,09^{b} \\
(0,002)\end{array}$ & $\begin{array}{c}4,38^{b} \\
(0,002)\end{array}$ & $\begin{array}{l}0,964^{\mathrm{ab}} \\
(0,001)\end{array}$ & $\begin{array}{l}8,44^{\mathrm{abc}} \\
(0,004)\end{array}$ & $\begin{array}{l}11,97^{\mathrm{ab}} \\
(0,009)\end{array}$ & $\begin{array}{l}15,42^{a b} \\
(0,013)\end{array}$ \\
\hline $500<\mathrm{CBT} \leq 600$ & $\begin{array}{c}3,57^{\mathrm{b}} \\
(0,010)\end{array}$ & $\begin{array}{c}3,11^{\mathrm{a}} \\
(0,004)\end{array}$ & $\begin{array}{c}4,37^{c} \\
(0,004)\end{array}$ & $\begin{array}{l}0,965^{\mathrm{a}} \\
(0,002)\end{array}$ & $\begin{array}{l}8,44^{\mathrm{abc}} \\
(0,009)\end{array}$ & $\begin{array}{l}12,01^{\mathrm{a}} \\
(0,015)\end{array}$ & $\begin{array}{l}15,45^{\mathrm{a}} \\
(0,030)\end{array}$ \\
\hline $600<\mathrm{CBT} \leq 750$ & $\begin{array}{c}3,55^{\text {bc }} \\
(0,009)\end{array}$ & $\begin{array}{c}3,09^{\mathrm{ab}} \\
(0,005)\end{array}$ & $\begin{array}{c}4,36^{\text {cd }} \\
(0,004)\end{array}$ & $\begin{array}{l}0,967^{a} \\
(0,002)\end{array}$ & $\begin{array}{c}8,42^{\mathrm{bc}} \\
(0,008)\end{array}$ & $\begin{array}{l}11,97^{a} \\
(0,013)\end{array}$ & $\begin{array}{l}15,46^{a} \\
(0,026)\end{array}$ \\
\hline $750<\mathrm{CBT} \leq 1000$ & $\begin{array}{l}3,57^{\mathrm{bc}} \\
(0,007)\end{array}$ & $\begin{array}{l}3,10^{\mathrm{ab}} \\
(0,004)\end{array}$ & $\begin{array}{c}4,35^{\mathrm{d}} \\
(0,003)\end{array}$ & $\begin{array}{l}0,968^{a} \\
(0,002)\end{array}$ & $\begin{array}{c}8,42^{\mathrm{c}} \\
(0,006)\end{array}$ & $\begin{array}{l}11,99^{a} \\
(0,011)\end{array}$ & $\begin{array}{l}15,46^{a} \\
(0,022)\end{array}$ \\
\hline CBT>1000 & $\begin{array}{c}3,61^{a} \\
(0,002)\end{array}$ & $\begin{array}{c}3,08^{b} \\
(0,001)\end{array}$ & $\begin{array}{c}4,32^{\mathrm{e}} \\
(0,001)\end{array}$ & $\begin{array}{c}0,966^{a} \\
(0,001)\end{array}$ & $\begin{array}{c}8,37^{d} \\
(0,002)\end{array}$ & $\begin{array}{c}11,98^{a} \\
(0,003)\end{array}$ & $\begin{array}{c}15,44^{a} \\
(0,007)\end{array}$ \\
\hline Média & 3,58 & 3,09 & 4,34 & 0,97 & 8,39 & 11,98 & 15,43 \\
\hline P-value ${ }^{1}$ & $<0,0001$ & $<0,0001$ & $<0,0001$ & $<0,0001$ & $<0,0001$ & $<0,0001$ & $<0,0001$ \\
\hline $\mathrm{CV}^{2}$ & 10,42 & 6,87 & 3,66 & 10,13 & 3,95 & 4,79 & 7,39 \\
\hline
\end{tabular}

Médias seguidas por letras distintas na mesma coluna diferem $(P<0,05)$ entre si pelo teste de Tukey

${ }^{1}$ Valor probabilístico

${ }^{2}$ Coeficiente de variação

mais frequentemente detectados ao nível de plataforma. Aacidez do leite pode ocasionar a coagulação da caseína e, assim, limitar o seu uso para o processamento em seus derivados.

A diminuição $(P<0,05)$ nos sólidos não gordurosos e $o$ aumento $(P<0,05)$ nos sólidos totais à medida que se elevou a CBT, provavelmente deve-se ao primeiro estar associado ao comportamento obtido para a lactose e o segundo com o comportamento encontrado para a gordura do leite (Tabela 2).

Os teores de gordura, proteína, minerais e sólidos totais apresentaram correlação positiva, ao passo que a lactose e os sólidos não gordurosos, correlação negativa com a CBT (Tabela 3). Por outro lado, não houve correlação significativa entre CCS e CBT (Tabela 3). Isso apenas reforça os diferentes comportamentos do úbere frente aos agentes causadores da mastite subclínica, ou microbiota residente.

Todavia, as correlações foram de baixa magnitude e sem significado prático. Analisando os resultados dos coeficientes de determinação $\left(R^{2}\right)$, pode-se constatar que a variação dos componentes em função da CBT atingiu no máximo 3,92\% para a lactose, seguido de $1,23 \%$ para a gordura, 1,04\% para SNG, 0,022 para proteínas e 0,020 para ST (Tabela 3 ). Resultados semelhantes da correlação entre proteína e lactose com o log da CBT foram reportados por Bueno et al. (2008). Entretanto, estes autores relataram correlação negativa entre a gordura e o log da CBT, o que refletiu na ausência de significância na correlação desta variável com os sólidos totais. Por outro lado, neste estudo, observa-se correlação positiva da gordura com o log da CBT, o que, por sua vez, repercutiu na correlação positiva observada para os sólidos totais frente a esta variável (Tabela 3).

Apesar da facilidade de degradação, principalmente da lactose (Santos e Fonseca, 2007) e da elevada contaminação de algumas amostras, os percentuais de redução podem ser considerados baixos, o que se refletiu nos baixos coeficientes de correlação linear (Tabela 3). Isto se deve, segundo Bueno et al. (2008), provavelmente ao fato de que o leite estava armazenado em condições de refrigeração, o que diminuiu a velocidade de crescimento bacteriano e, consequentemente, a utilização dos nutrientes.

Pode-se observar que não houve correlação significativa entre o logaritmo natural da CBT normal e as variáveis climáticas (temperatura ambiente, umidade relativa do ar e precipitação pluviométrica) (Tabela 4), fato que pode ser justificado, pela relação existente entre estas variáveis com a maior pressão de infecção por micro-organismos ambientais, os quais estão mais relacionados com casos de mastite clínica, como os causados por Escherichia coli ou Streptococcus uberis (Santos e Fonseca, 2007).

Considerando que normalmente o leite de vacas com mastite clínica é descartado, esses casos não influenciariam a CBT do leite de tanques de expansão. Corroborando com os achados deste estudo, Bueno et al. (2008) reportaram ausência de correlação $(P>0,05)$ entre a CBT e a temperatura ambiente. Por outro lado, estes mesmos autores encontraram correlação significativa entre CBT e umidade relativa do ar $(r=0,76 ; P<0,01)$ e CBT e precipitação pluviométrica $(r=0,93 ; P<0,001)$. 
Tabela 3: Coeficientes de correlação ( $r$ ) e coeficientes de determinação $\left(R^{2}\right)$ dos teores de gordura, proteína, lactose, minerais, sólidos não gordurosos (SNG), sólidos totais (ST), logaritmo natural da contagem bacteriana total (CBT) com o escore linear de células somáticas (ECS)

\begin{tabular}{|c|c|c|}
\hline \multirow{2}{*}{ Variável } & \multicolumn{2}{|c|}{$\begin{array}{c}\mathrm{CBTt} \\
\left(\log \mathrm{UFC} \mathrm{mL}^{-1}\right)\end{array}$} \\
\hline & $r^{(2)}$ & $\mathrm{R}^{2(3)}$ \\
\hline Gordura (\%) & $0,111^{\text {*** }}$ & 0,01232 \\
\hline Proteína (\%) & $0,015^{\star *}$ & 0,00022 \\
\hline Lactose (\%) & $-0,198^{* * *}$ & 0,03920 \\
\hline Minerais (\%) & $0,013^{\star *}$ & 0,00016 \\
\hline SNG (\%) & $-0,102^{* * *}$ & 0,01040 \\
\hline ST (\%) & $0,014^{* *}$ & 0,00020 \\
\hline (1)ECS (céls mL ${ }^{-1}$ ) & $0,006^{\text {ns }}$ & 0,00004 \\
\hline
\end{tabular}

ns Não significativo; * $\mathrm{P}<0,05 ;{ }^{* *} \mathrm{P}<0,01$; ${ }^{* *} \mathrm{P}<0,001$

${ }^{1} E$ Escore linear da contagem de células somáticas (SHOOK, 1993)

${ }^{2}$ Coeficiente de correlação linear simples

${ }^{3}$ Coeficiente de determinação

Tabela 4: Coeficientes de correlação $(r)$ e coeficientes de determinação $\left(R^{2}\right)$ do logaritmo natural da contagem bacteriana total (CBT) normal com as médias mensais das variáveis meteorológicas (temperatura média, umidade relativa do ar e precipitação pluviométrica)

\begin{tabular}{ccc}
\hline \multirow{2}{*}{ Variáveis Climáticas } & \multicolumn{2}{c}{ CBT } \\
\cline { 2 - 3 } & $\mathrm{r}^{(1)}$ & $\mathrm{R}^{2(2)}$ \\
\hline Temperatura média $\left({ }^{\circ} \mathrm{C}\right)$ & $0,190^{\text {ns }}$ & 0,03610 \\
Umidade relativa do ar $(\%)$ & $-0,286^{\text {ns }}$ & 0,08179 \\
Precipitação $(\mathrm{mm})$ & $0,057^{\text {ns }}$ & 0,00325 \\
\hline
\end{tabular}

ns não significativo; ${ }^{*} P<0,05,{ }^{* *} P<0,01,{ }^{* * *} P<0,001$

(1) Coeficiente de correlação linear simples

(2) Coeficiente de determinação

$\mathrm{Na}$ análise de variância multivariada houve diferença $(P<0,05)$ entre os vetores de médias para as classes de CBT, tanto pelo teste Wilks quanto pelos testes Pillai, Hotelling-Lawley e Roy. Os três primeiros autovalores foram significativos pelo teste da razão de verossimilhança, sendo que o primeiro autovalor explicou $75,60 \%$ e o segundo $18,21 \%$, ou seja, os dois primeiros autovalores explicaram $93,81 \%$ da variação total dos dados (Figura 1).

A análise de componentes principais permite visualizar a proximidade/similaridade ou distância/dissimilaridade entre as diferentes classes de CBT (Figura 1). A partir desta análise, dois novos conjuntos de dados foram gerados: os "scores", que trazem informações sobre os tratamentos, e os "loadings", que mostram as correlações existentes entre as variáveis e os componentes principais, sendo que a representação destes dois conjuntos de dados foi realizada através de um gráfico "biplot" (Figura 1).
Dessa maneira, as variáveis que explicaram a variabilidade no eixo $\times$ (componente principal 1) foram gordura, minerais, lactose e ECS, ao passo que a variável que explicou a variabilidade no eixo y (componente principal 2) foi a proteína. Logo, a partir das correlações dos componentes principais com as variáveis, podese observar que somente a proteína está correlacionada com o componente principal 2, que, por sua vez, explica em menor proporção a variância total dos dados analisados (Figura 1). Isto ocorre, provavelmente, segundo Bueno et al. (2008), devido à grande demanda metabólica exigida pelos micro-organismos para a degradação deste componente.

Todavia, conforme inspeção gráfica visual não se pode concluir sobre o número ideal de grupos entre tratamentos. Dessa forma, através da análise de agrupamento (Cluster Analysis) permitiu constatar-se que o número ideal de grupos formados entre tratamentos foram quatro, dos quais um grupo englobando as classes de CBT 2 e 3 e outro as classes 4, 5 e 6 (tratamentos) (Figura 1). Entretanto, além da formação destes agrupamentos, observa-se a formação de 2 grupos com elevada dissimilaridade. Estes grupos distintos são formados pelo tratamento 1 (CBT $\leq 50.000$ UFC mL-1) e o tratamento 7 (CBT > 1.000.000 UFC $\mathrm{mL}^{-1}$ ), e diferem entre si, principalmente em relação ao eixo $x$ (componente principal 1). Dessa maneira, o grupo formado pelos maiores valores de CBT (CBT > 1.000.000 UFC mL-1) possui concentrações superiores de gordura, minerais e ECS e menores valores de lactose, quando comparado com o grupo de menores valores de CBT (CBT $\leq 50.000$ UFC $\mathrm{mL}^{-1}$ ). Porém, o aumento nos teores de gordura, proteína e minerais à medida que se eleva a CBT, não pode ser considerado favorável à qualidade do leite, visto que o aumento da contaminação bacteriana, como dito anteriormente, ocorre como resultado de deficiências higiênico-sanitárias do processo produtivo do leite, bem como pelo aumento da incidência de mastite subclínica por bactérias do gênero estreptococos, o que acarretaria em diminuição do volume de leite produzido e consequente concentração relativa dos teores de gordura, proteína e minerais, fato este evidenciado pela correlação positiva encontrada entre o ECS e o componente principal 1. A correlação negativa achada entre o componente principal 1 e a lactose demonstra redução desta variável por ação direta de bactérias presentes no leite. Assim, apesar de ter sido encontrado um aumento na concentração total de gordura e proteína, a intensa atividade bacteriana caracterizada pela diminuição da lactose pode estar causando alterações qualitativas destas variáveis.

Portanto, o leite com CBT superiores a 50.000 até 500.000 UFC $\mathrm{mL}^{-1}$, e ainda de valores acima de 500.000 até 1.000 .000 UFC $\mathrm{mL}^{-1}$ apresentam a mesma qualidade química e contagem de células somáticas, ou seja, não se justifica a criação de extratos intermediários nestas amplitudes, para avaliação do efeito da CBT sobre estas variáveis.

Os padrões legais mínimos de CBT de 600.000 UFC mL-1 (atual limite brasileiro) e de 500.000 UFC mL-1 (limite brasileiro proposto para o dia 30 de junho de 2014 a 30 de junho de 2016) não resultariam em melhorias na qualidade química do leite, enquanto o limite proposto pelos países membros da União Europeia, Nova Zelândia, Austrália, Estados Unidos e ainda pela norma brasileira a partir do dia $1^{\circ}$ de julho de 2016, de 100.000 UFC $\mathrm{mL}^{-1}$ (Bulletim, 2006), se considerados como obrigação de quem produz, acarretariam melhorias significativas destes 
indicadores de qualidade. Os limites mais rígidos adotados pelos Estados Unidos da América (EUA), países membros da União Européia (UE), Nova Zelândia e Austrália são reflexos de seus programas de pagamento por qualidade que estão em processo gradativo de implantação desde a década de 1970, o que, por sua vez, posiciona estes países entre os principais exportadores de lácteos do mundo.

Diante do exposto, podemos constatar que o programa de pagamento por qualidade do Canadá, que também se destaca como exportador de lácteos está mais adequado que o adotado pelos EUA, países membros da União Europeia, Austrália e Nova Zelândia, pois levam em consideração o limite de 50.000 UFC mL-1 (Buletim, 2006), o que acarretaria em melhorias significativas na qualidade do leite e derivados produzidos com esta matéria-prima, principalmente, porque estes países são destacados exportadores de queijo e manteiga e, como dito anteriormente, a ação de lipases e proteases bacterianas nas frações lipídicas e proteicas, diminuiriam o rendimento industrial e qualidade destes derivados lácteos (Figura 1).

Da mesma maneira, a Dinamarca também considera limites mais rígidos de remuneração do leite, resultando em 4 classes distintas em relação a CBT (classe 1: CBT menor que 30.000 UFC mL-1; classe 2: CBT menor que $50.000 \mathrm{UFC} \mathrm{mL}^{-1}$; classe 3: CBT menor que 200.000 UFC mL-1; classe 4: CBT maior que 200.000 UFC mL-1) (Bulletim, 2006).

Assim, sistemas de bonificação e penalização que levam em consideração limites de CBT mais rígidos, como os propostos pelo Canadá e Dinamarca, acarretariam em melhorias significativas da qualidade do leite e seus derivados, conforme fica destacado na Figura 1.

Isto evidencia que somente o cumprimento de normas regulatórias, sem levar em consideração sistemas mais rígidos de bonificações e penalizações, não é suficiente para promover a melhoria na qualidade do leite brasileiro e reduzir prejuízos industriais impactantes ocasionados pelo alto efetivo microbiano, como: acidificação e coagulação, produção de gás, geleificação, sabor amargo, coagulação sem acidificação, aumento da viscosidade, alteração de cor, produção de sabores, odores variados, dentre outros, os quais diminuem a vida de prateleira e o rendimento industrial dos derivados lácteos (Gigante, 2004).

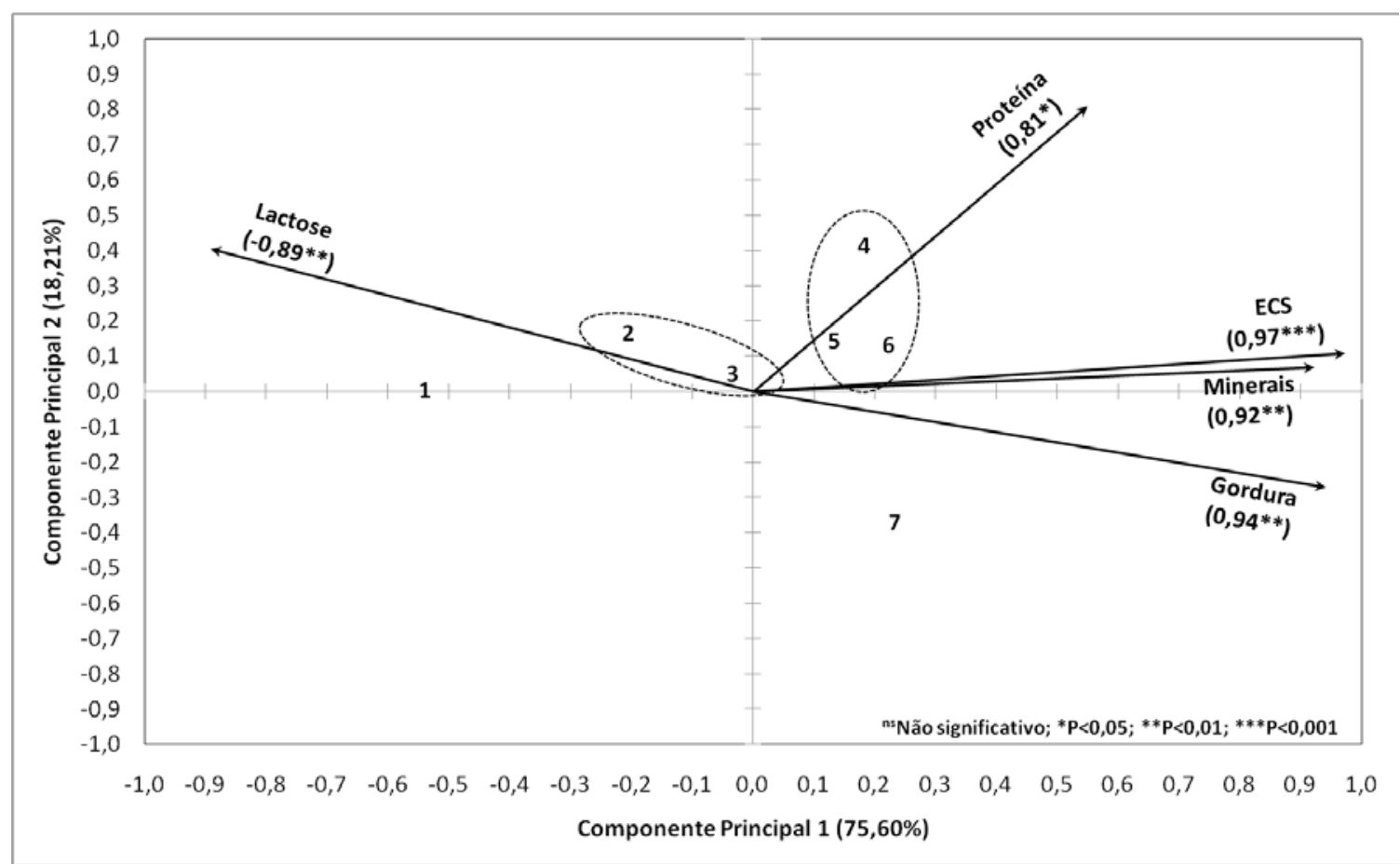

Figura 1: Projeção bidimensional das diferentes classes de CBT (1: CBT $\leq 50.000$ UFC mL ${ }^{-1} ; 2: 50.000<$ CBT $\leq 100.000$ UFC $\mathrm{mL}^{-1}$; 3: $100.000<\mathrm{CBT} \leq 500.000$ UFC mL-1 $^{-1} 4: 500.000<\mathrm{CBT}^{2} 600.000 \mathrm{UFC} \mathrm{mL}^{-1} ; 5: 600.000<\mathrm{CBT}^{2} 750.000$ UFC mL-1; $6: 750.000$ $<\mathrm{CBT} \leq 1000.000$ UFC mL-1; e 7: CBT > 1.000.000 UFC mL-1) e as variáveis gordura, proteína, lactose, minerais e escore linear de células somáticas $\left(E C S=\left[\log _{2}(C C S / 100)\right]+3\right)$, com seus respectivos coeficientes de correlação e nível de significância (entre parênteses) em função dos dois primeiros componentes principais 


\section{Conclusões}

A elevação da CBT está diretamente correlacionada com o aumento dos teores de gordura, proteína, minerais e sólidos totais, o que não deve ser considerado favorável à qualidade do leite, pois, o incremento dos valores de CBT é influenciado por todos os utensílios que entram em contato com o leite, pele de tetos e úbere, bem como glândula mamária infectada, principalmente por estreptococos causadores de mastite subclínica, o que, na análise das distintas classes de CBT, explica o aumento simultâneo da CCS, portanto, estes efeitos provavelmente são decorrentes da diminuição da produção de leite pelo aumento da incidência de mastite subclínica por bactérias do gênero estreptococos. Por outro lado, o aumento da contaminação bacteriana está inversamente correlacionado com

\section{Referências}

ANDRADE, U.V.C.; HARTMAN, W.; MASSON, M.L. Isolamento microbiológico, contagem de células somáticas e contagem bacteriana total em amostras de leite. Ars Veterinaria, v. 25, n. 3, p. 129-135, 2009.

BRASIL. Instrução Normativa n. 51 de 18 de setembro de 2002. Dispões sobre regulamentos técnicos aplicados ao leite cru refrigerado e pasteurizado. Diário Oficial da União, Brasília, DF, 20 set. 2002. Seção 1, n. 183, p.13-22.

BRASIL. Instrução Normativa n. 62 de 29 de dezembro de 2011. Dispõe sobre regulamentos técnicos de produção, identidade e qualidade do leite tipo A, leite Cru refrigerado, leite pasteurizado e do regulamento técnico de coleta de leite cru refrigerado e seu transporte a granel. Disponível em: <http://www.sindilat.com.br/ gomanager/arquivos/IN62_2011(2).pdf> Acesso em: 05/05/2012.

BULLETIN of the International Dairy Federation. Payment systems for ex-farm milk. Brussels: International Dairy Federation, 2006. 106 p. Bulletin 403/2006.

BUENO, V.F.F.; MESQUITA, A.J.; OLIVEIRA, A.N.; NOCOLAU, E.S.; NEVES, R.B.S. Revista Brasileira de Ciência Veterinária, v.15, n. 1, p. 40-44, 2008.

CHEN, L.; DANIEL, R.M.; COOLBEAR, T. Detection and impact of protease and lipase activities in milk powders. International Dairy Journal, v. 13, n. 4, p. 55-275, 2003.

GIGANTE, M.L. Importância da qualidade do leite no processamento de produtos lácteos. In: CONGRESSO BRASILEIRO DE QUALIDADE DO LEITE, 1., 2004, Passo Fundo. Anais eletrônicos...Passo Fundo:UPF, 2004. CD-ROM.

HANUŠ, O.; VEGRICHT, J.; FRELICH, J.; MACEK, A.; BJELKA, M.; LOUDA, F.; JANU゚, L. Analysis of raw milk quality according to free fatty acid contents in the Czech Republic. Czech Journal Animal Science, v. 53, n. 1, p. 17-30, 2008.

HARMON, R.J. Physiology of mastitis and factors affecting somatic cell counts. Journal of Dairy Science, v. 77 , n. 7, p. 2103-2112, 1994.

LOPES JÚNIOR, J.E.F; LANGE, C.C.; BRITO, M.A.V.P.; SANTOS, F.R.; SILVA, M.A.S.; MORAES, L.C.D.; SOUZA, G.N. Relationship between total bacteria counts and somatic cell counts from mammary quarters infected by mastitis pathogens. Ciência Rural, v. 42, n. 4, p. 691-696, 2012. os teores de lactose, devido à ação direta de bactérias presentes no leite, o que ocasionou uma diminuição concomitante dos sólidos não gordurosos. Todavia, as correlações foram de baixa magnitude e sem significado prático. Não houve relação significativa entre o logaritmo natural da CBT normal e as variáveis climáticas (temperatura ambiente, umidade relativa do ar e precipitação pluviométrica). A análise de componentes principais seguida da análise de agrupamento permitiu constatar que leites com CBT superiores a 50.000 até 500.000 UFC mL-1, e ainda de valores acima de 500.000 até 1.000 .000 UFC mL $\mathrm{mL}^{-1}$ apresentam a mesma qualidade química e contagem de células somáticas, não justificando a estratificação de intervalos nestas amplitudes de variações, para avaliação do efeito da CBT sobre indicadores de qualidade do leite.

MA, Y.; RYAN, C.; BARBANO, D.M.; GALTON, D.M.; RUDAN, M.A.; BOOR, K.J. Effects of somatic cell count on quality and shelflife of pasteurized fluid milk. Journal of Dairy Science, v. 83, n. 2, p. 264-274, 2000.

MACHADO, P.F.; PEREIRA, A.R.; SARRÍEZ, G.A. Composição do leite de tanques de rebanhos brasileiros distribuídos segundo sua contagem de células somáticas. Revista Brasileira de Zootecnia, v. 29, n. 6, p. 1883-1886, 2000.

MARTINS, M.L.; ARAÚJO, E.F.;MANTOVANI, H.C.; MORAES, C.A. Detection of the apr gene in proteolytic psychrotrophic bacteria isolated from refrigerated raw milk. International Journal of Food Microbiology, v. 102, n. 2, p. 203-211, 2005.

NERO, L.A.; MATTOS, M.R.; BELOTI, V.; BARROS, M.A.F.; PINTO, J.P.A.N.; ANDRADE, N.J.; SILVA, W.P.; FRANCO, B.D.G.M. Leite cru de quatro regiões leiteiras brasileiras: perspectivas de atendimento dos requisitos microbiológicos estabelecidos pela Instrução Normativa 51. Ciência e Tecnologia de Alimentos, Campinas, v. 25, n. 1, p. 191-195, 2005.

SANTOS, M.V.; FONSECA, L.F.L. Estratégia para controle de mastite e melhoria da qualidade do leite. 2. ed. Barueri, SP: Manole, 2007. 314 p.

SHOOK, G.E. Genetic improvement of mastitis through selection on somatic cell count. The Veterinary Clinics of North America: Food Animal Practice, v. 9, n. 3, p. 563-581, 1993.

STATISTICAL ANALYSIS SYSTEM - SAS. The SAS system for windows. v. 9.0 Cary: SAS Institute Inc., 2002.

TEBALDI, V.M.R.T;; OLIVEIRA, T.L.C.; BOARI, C.A.; PICCOLI, R.H. Isolamento de coliformes, estafilococos e enterococos de leite cru provenientes de tanques de refrigeração comunitários: identificação, ação lipolítica e proteolítica. Ciência e Tecnologia de Alimentos, v. 28, n. 3, p. 753-760, 2008.

VIDAL-MARTINS, A. A.; ROSSI JÚNIOR, O. D.; REZENDE-LAGO, N. C. Microrganismos heterotróficos mesófilos e bactérias do grupo Bacillus cereus em leite integral submetido a ultra alta temperatura. Arquivo Brasileiro de Medicina Veterinária e Zootecnia, v. 57, n. 3, p. 396-400, 2005.

ZADOKS, R.N.; GONZALEZ, R.N.; BOOR, K.J.; SCHUKKEN, Y.H. Mastitis-causing Streptococci are important contributors to bacterial counts in raw bulk tank milk. Journal Food Protection, v. 67, n. 12, p. 2644-2650, 2004. 